NOAA

National Marine

Fisheries Service
Fishery Bulletin

2 established 1881 ๙
Spencer F. Baird

First U.S. Commissione of Fisheries and founder of Fishery Bulletin
Abstract-Recent acoustic tagging of juvenile Chinook salmon (Oncorhynchus tshawytscha) in the southern portion of California's Sacramento-San Joaquin Delta has revealed extremely low survival rates $(<1 \%)$, possibly due to predation by piscivorous fishes. We evaluated predation as a cause of low survival by designing and testing freely floating GPSenabled predation-event recorders (PERs) baited with juvenile Chinook salmon. We estimated predation rates and identified predation locations within a 1-kilometer reach of the Lower San Joaquin River. We modeled the relationship between time to predation and environmental variables with a Cox proportional hazards analysis that accounts for censored data. Our results indicated that an increase of $1 \mathrm{~m} / \mathrm{s}$ in water velocity elevated the minute-by-minute hazard of predation by a factor of 9.6. Similarly, each increase in median depth decreased the predation hazard by a factor of 0.5 . The mean relative predation rate in the study area was $15.3 \%$ over 9 sampling events between March and May 2014. Waterproof video cameras attached to a subset (48 of 216) of PERs successfully identified predator species $25 \%$ of the time. Our GPS-enabled PERs proved to be an inexpensive and reliable tool, which quantified predation, identified predation locations, and provided complementary information for acoustic telemetry and predator diet studies.

Manuscript submitted 9 July 2015. Manuscript accepted 3 February 2016. Fish. Bull. 114:179-185 (2016).

Online publication date: 23 February 2016. doi: 10.7755/FB.114.2.5

The views and opinions expressed or implied in this article are those of the author (or authors) and do not necessarily reflect the position of the National Marine Fisheries Service, NOAA.

\title{
Development of underwater recorders to quantify predation of juvenile Chinook salmon (Oncorhynchus tshawytscha) in a river environment
}

\author{
Nicholas J. Demetras (contact author) ${ }^{1}$ \\ David D. Huff 2 \\ Cyril J. Michel ${ }^{1}$ \\ Joseph M. Smith ${ }^{3}$ \\ George R. Cutter 4 \\ Sean A. Hayes 5 \\ Steven T. Lindley 5 \\ Email address for contact author: nicholas.demetras@noaa.gov \\ 1 University of California, Santa Cruz \\ Affiliated with Southwest Fisheries Science \\ Center \\ National Marine Fisheries Service, NOAA \\ 110 Shaffer Road \\ Santa Cruz, California 95060 \\ 2 Point Adams Research Station \\ Fish Ecology Division \\ Northwest Fisheries Science Center, NOAA \\ PO Box 155, Hammond, OR 97121 \\ ${ }^{4}$ Fisheries Resource Division \\ Southwest Fisheries Science Center \\ National Marine Fisheries Service, NOAA \\ 8901 La Jolla Shores Drive \\ La Jolla, California 92037-1508 \\ ${ }^{5}$ Fisheries Ecology Division \\ Southwest Fisheries Science Center \\ National Marine Fisheries Service, NOAA \\ 110 Shaffer Road \\ Santa Cruz, California 95060 \\ 3 School of Aquatic and Fishery Sciences \\ University of Washington \\ 1122 NE Boat Street \\ Seattle, Washington 98105
}

Predation on juvenile Chinook salmon (Oncorhynchus tshawytscha) and other native fishes within California's Sacramento-San Joaquin Delta has raised considerable debate over the last several decades (Bennet and Moyle, 1996; Mount et al., 2012). Traditionally, juvenile Chinook salmon survival within this delta has been estimated by using acoustic tagging data or coded-wire tag recoveries from mid-water trawls (Brandes and McLain, 2001; Newman and Rice, 2002; Buchanan et al., 2013; Michel et al., 2013; Pyper et al., 2013; Newman, 2003; Newman ${ }^{1}$ ). It is currently

${ }^{1}$ Newman, K. B. 2008. An evaluation of the four Sacramento-San Joaquin River Delta juvenile salmon survival studies, not clear what proportion of juvenile salmonid mortality may be directly attributed to fish predation. It is also difficult to interpret results regarding population-level survivorship in the Delta because these data have limited spatial scales, used various tagging methodologies, and do not clearly connect tag loss or mortality to predation (Grossman et al. ${ }^{2}$ ). Be-

181 p. U.S. Fish Wildl. Serv., Stockton, CA. [Available at website, accessed October 2014.]

2 Grossman, G. D., T. Essington, B. Johnson, J. Miller, N. E. Monsen, and T. N. Pearsons. 2013. Effects of fish predation on salmonids in the Sacramento River-San Joaquin Delta and associated ecosystems, 71 p. [Available at website, accessed October 2014.] 
cause most survival data come from acoustic tagging studies, it is essential to improve our understanding of the underlying cause of mortality events (i.e. predation, environmental, or other) from these types of instruments. We developed a tool to address this research need by designing floating, baited, predation-event recorders (PERs). These recorders allow estimation of relative predation rates in various environments, and reveal information about mortality produced by different species of fish predators.

Our objectives were to investigate the feasibility of 1) developing and constructing a passive, baited, GPSenabled PER, 2) evaluating relative risk of predation mortality and 3) observing and identifying individual predators and associated predation events. We estimated relative predation mortality and identified predation hot spots upon juvenile Chinook salmon to compliment ongoing acoustic telemetry surveys. We were able to accurately identify the location of individual predation events, reliably identify predators, and the recorder system was easily deployed and retrieved by a boat-based crew of 2 people.

\section{Materials and methods}

\section{PER construction}

PERs were constructed from an approximately $75 \mathrm{~cm}$ length of $76 \mathrm{~mm}$ diameter, schedule 40 polyvinyl chloride (PVC) pipe. The bottom end was fitted with a PVC cap which was glued in place and the top end was fitted with a two part threaded, removable cap. Attached to the top cap was a GARMIN ${ }^{\circledR} \mathrm{TT}^{\mathrm{TM}} 10^{3}$ GPS transponder (available at website) set to update and record its position every five seconds. A predation-activated timer was attached to the bottom cap. The design of the timer, similar to that of Somerton et al. (1988), is connected to a baited line attached to a magnet, which is slotted inline into a receptacle on the timer, housing a magnetic switch (Fig. 1). When the bait is pulled, the magnet is removed, activating the timer that records the precise timing of the predation event. All GPS trackers were controlled and their tracks recorded with a GARMIN ${ }^{\circledR}$ Alpha $100^{\circledR 1}$ handheld base-station unit plugged into a laptop computer located on board the boat. Up to 20 GPS trackers may be tracked simultaneously in real-time with one Alpha $100^{\circledR}$ handheld unit, as long as all trackers are within approximately 14 kilometers line-of-sight. More trackers can be tracked if multiple base stations are used.

Attached to each predation timer was a $50 \mathrm{~cm}$ length of $3.6 \mathrm{~kg}$ breaking-strength fluorocarbon leader. A sub yearling fall-run juvenile Chinook salmon from the Mokelumne River fish hatchery was attached to the distal end of the fluorocarbon leader by means of

\footnotetext{
${ }^{3}$ Mention of trade names or commercial companies for identification purposes only and does not imply endorsement by the National Marine Fisheries Service.
}

a loop threaded through the mouth and operculum. A seven-gram split-shot style weight was placed approximately $10 \mathrm{~cm}$ above the fish. Approximately $2.25-\mathrm{kg}$ of lead shot was placed inside the bottom of each PER as ballast, which served to keep PERs upright while submerging all but the upper most 10 to $15 \mathrm{~cm}$, where the GPS receiver was attached. GoPro ${ }^{3}$ underwater cameras, with 64 gigabyte storage SanDisk ${ }^{3}$ memory cards (available at website), were attached to a subset of 3 PERs opposite the predation timer and aimed directly at the attached smolt (Fig. 1). PERs were spray painted in a green and brown camouflage pattern to reduce visibility and obtrusiveness in the upper water column, but the top 10 to $15 \mathrm{~cm}$ above the water line were painted a bright safety orange and marked with reflective tape for easier visual identification by passing watercraft. Onset@ $\mathrm{HOBO}{ }^{3}$ pendant temperature and light data loggers (available at website) were attached to each PER (Fig. 1) so that we could relate environmental variables to predation events.

\section{Field trials}

All field trials were conducted within a $1-\mathrm{km}$ study site (lat. $37.806^{\circ} \mathrm{N}$, long. $121.317^{\circ} \mathrm{W}$, lat. $37.799^{\circ} \mathrm{N}$, long. $\left.121.313^{\circ} \mathrm{W}\right)$ on the lower San Joaquin River located approximately $1.5 \mathrm{~km}$ downstream from Mossdale, CA. The depth of the sampling site ranged from $3.65 \mathrm{~m}$ to $0.6 \mathrm{~m}$ and had a mean depth of $1.98 \mathrm{~m}$; the minimum effective depth of the PERs was $0.6 \mathrm{~m}$, which represented approximately $88 \%$ of the total wetted stream channel. Depth of the entire sampling site was measured and mapped with boat-mounted sonar. River velocities ranged from $0.49 \mathrm{~m} / \mathrm{s}$ to $-0.32 \mathrm{~m} / \mathrm{s}$ (mean velocity: $0.27 \mathrm{~m} / \mathrm{s}$. Negative values denote a flood tide and reversal of flow going upstream. Channel width ranged from approximately $70 \mathrm{~m}$ to $90 \mathrm{~m}$. The sinuosity index (SI) of the study reach was 1.21 . SI is a measurement of a river or stream's deviation from the shortest possible downslope path. A value of 1.0 indicates a perfectly straight channel, whereas increasing values of 1 are representative of increased meandering (Mueller, 1968). Ten PERs were repeatedly deployed on 9 separate trials, either one hour before sunrise or one hour before sunset by a 2-person boat crew, all trackers remained within line of site of the boat while deployed. Each trial consisted of 2 separate deployments mid channel; if a tether became beached or fouled it was promptly retrieved and redeployed at mid-channel. Each re-deployment was considered a unique deployment on its own.

The procedure for deploying PERs was 1) activation of GPS transponders/GoPro cameras (30 sec/PER), 2) attachment of the salmon smolt to predation timers (1 min/timer), 3) release of PERs (1 min/PER), 4) transit of PER through study site (45 min. to $1 \mathrm{~h}$. depending upon river velocity), 5) retrieval of PERs and recording of timer data (20-30 min). Digital predation timers were immediately recorded upon retrieval. The cumulative time spent preparing, deploying, fishing, and re- 


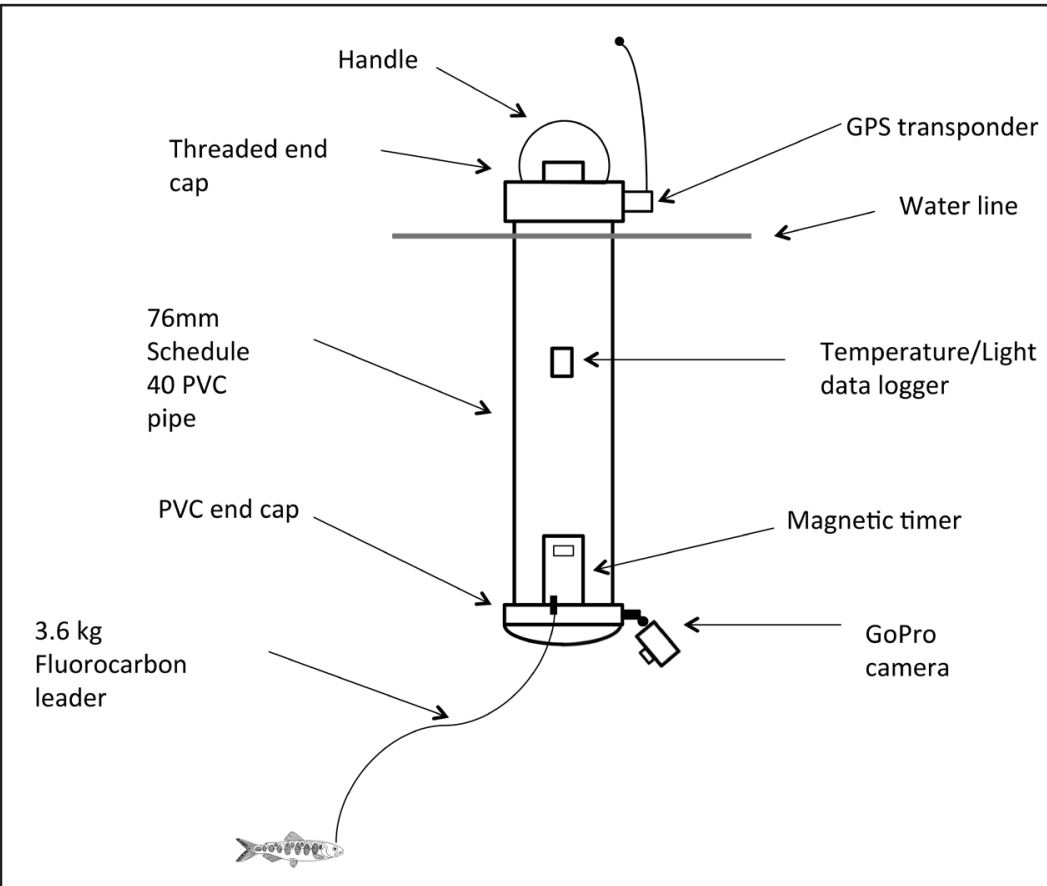

Figure 1

Schematic of a predation-event recorder (PER) with attached salmon smolt as bait. PERs were used to evaluate predation rates and environmental variables in the Sacramento-San Joaquin Delta, California from March through May of 2014. vidual PER sampling time. Video footage was later viewed to confirm predation events and to identify predator species.

The relationship between survival of tethered smolt, exposure time, and environmental factors was modeled with a Cox proportional-hazards regression for censored data (Cox, 1972) by using the OIsurv package, vers. 0.2 (Diez, 2013) in $\mathrm{R}$ statistical software, vers. 3.2.0 ( $\mathrm{R}$ Core Team, 2015). Before model construction, we examined correlation coefficients of candidate covariate pairs to identify collinearity and only included one variable of a pairwise comparison that had correlations greater than 0.7 (Dormann et al., 2013). The candidate covariates for the model were total distance traveled (m), median light intensity (lux), median depth $(\mathrm{m})$, standard deviation of depth (m), median water temperature $\left({ }^{\circ} \mathrm{C}\right)$, and median water velocity $\left(\mathrm{ms}^{-1}\right)$. Akaike's information criterion (AIC; Burnham and Anderson, 2002) was used to select the most parsimonious model with the best fit to the data in a forward and backward step-wise fashion. Model residuals were examined to evaluate the model fit. trieving ten PERs by a 2-person boat crew ranged from 90 to 115 minutes.

Owing to extremely low flows during our study period in the spring of 2014, the lower San Joaquin River was under direct tidal influence over the course of the study and experienced a mixed, semidiurnal tidal pattern. The tidal nature of the San Joaquin River during this period required extra effort to determine the correct mid-channel placement of the PERs so that they would remain within the site for approximately 45 minutes or longer. If a PER did not remain within a study site for at least 45 minutes, or became beached or otherwise fouled, it was promptly retrieved, re-baited and redeployed within the study site.

\section{Data processing and analysis}

PER GPS transponders recorded a location every 5 seconds, whereas predation timers recorded the timing of predation events. By cross-referencing predation data from the predation timer (time of predation) with PER GPS data (time/latitude/longitude) we were able to obtain locations of each predation event. GoPro video footage was captured with a widescreen aspect ratio of $16: 9$, resolution $1920 \times 1080$ (1080p HD "Superview"), at 30 frames per second at the low light setting. Each camera produced on average approximately 12 to 20 gigabytes of data per deployment depending on indi-

\section{Results}

We conducted 216 PER deployments between late March and late May 2014. Of the 216 deployments, we recorded 33 total predation events (15\%), 12 of which were captured on video by the GoPro camera. Throughout the study we were able to easily combine the timer data with the corresponding GPS data to produce accurate maps of PER pathways and predation event locations within the study site (Fig. 2).

Water conductivity and water velocity were collinear at $r=-0.75$. Water conductivity was excluded, however, from the analysis because it was within the physiological range of both juvenile Chinook salmon and predators and was assumed to have minimal impact on their ability to forage. AIC model selection indicated that water velocity and median depth best explained variation in predation rate. The coefficient for water velocity was 2.3 and median depth was -0.7 . The exponentiated coefficient for water velocity was 9.6 and median depth was 0.5. Exponentiated coefficients are interpretable as multiplicative effects on the hazard. For example, by holding the median depth constant, an additional meter per second increase in water velocity increases the minute-by-minute hazard of predation by a factor of 9.6. Similarly, each increase in median depth decreases the hazard by a factor of 0.5 . The likelihood-ratio [LR] 

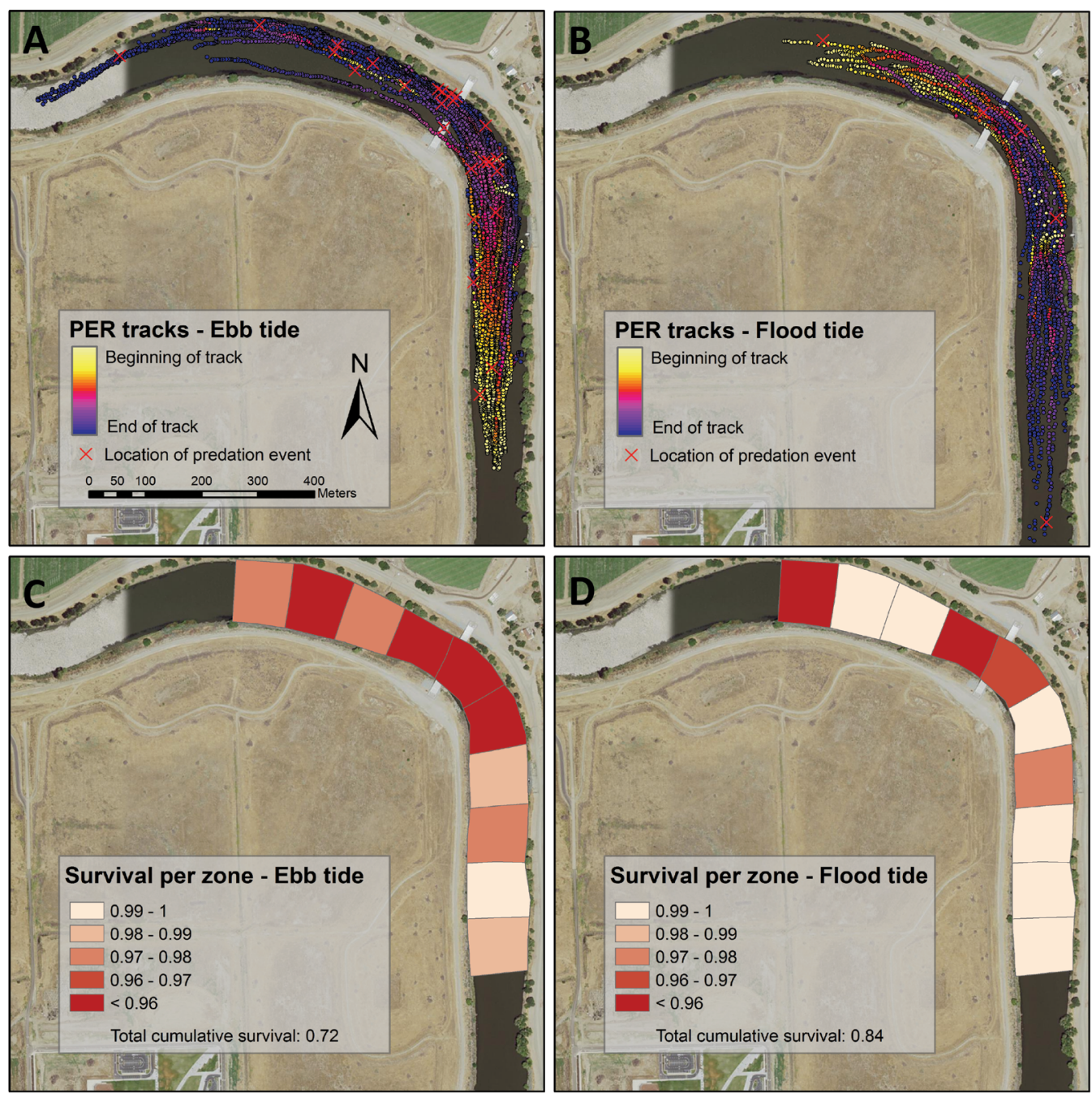

Figure 2

Multipanel aerial photograph of the study site. (A) Individual PER tracks during ebb tide conditions. Red $\times$ 's denote individual locations of predation. (B) Individual PER tracks during flood tide conditions. Red x's denote individual locations of predation. (C) Study site segmented into 100-m sections. Color coding denotes survival per 100-m sections during ebb tide conditions. (D) Study site segmented into $100-\mathrm{m}$ sections. Color-coding denotes survival per $100 \mathrm{~m}$ sections during floodtide conditions.

test of the null hypothesis that the $\beta$ 's are zero was rejected ( $\mathrm{LR}=11.3,2 \mathrm{df}, P=0.004)$. The estimated distribution of survival times was calculated at the mean values of the covariates (Fig. 3). These indicated that the proportion of salmon that were preyed upon increased sharply from 20 to 30 minutes of exposure to predators. We plotted the distribution of survival times as they varied from the minimum (negative) to the maximum (positive) water velocities by $0.1 \mathrm{~m} / \mathrm{s}$ increments (Fig. 4). Predation was greatest with increasing positive water velocities and was lowest at the more negative water velocities.
From the PERs that were outfitted with cameras, we obtained 48 complete videos of individual deployments ( $22 \%$ of total) that resulted in approximately 800 gigabytes of raw data. Of these, tripped timers in combination with missing smolts indicated that 12 were predation events. Video analysis confirmed the predation and a fish was seen preying upon the smolt in each instance. Three of the events captured on video were confirmed to be predation by striped bass (Morone saxatilis), and the remaining 8 predators were not identifiable to species. Analysis of the video data revealed that if the timer was activated and the 


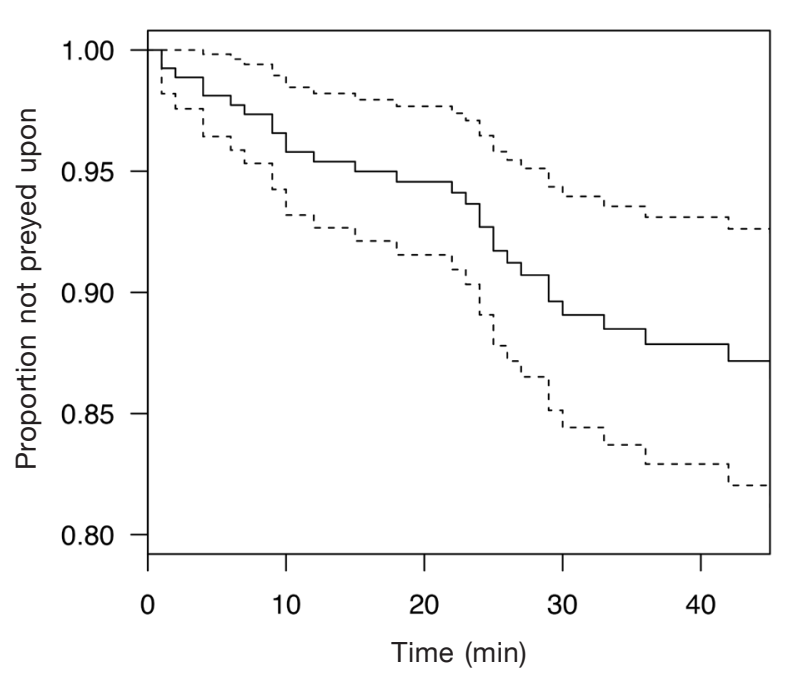

Figure 3

Estimated survival function for the Cox regression of time to predation on water velocity and median depth. Broken lines indicate a point-wise $95 \%$ confidence interval about the survival function.

smolt was missing, it was a confirmed predation event. Video analysis also indicated that the tethered smolts remained in an upright and active swimming position during deployments.

\section{Discussion}

Predation upon juvenile Chinook salmon in the Sacramento-San Joaquin Delta and resulting effects on population level has been a topic of debate. The presumption that predation may play a significant role in survival was investigated with the use of statistical models on winter-run Chinook salmon by Lindley and Mohr (2003) and Hendrix. ${ }^{4}$ Neither analysis implied a substantial link between striped bass predation and Chinook salmon survival. However, the quality of the data used in statistical analyses is a major determinant of the strength of the results, and diet data for many piscine predators in the delta is lacking (Grossman et $a .^{2}$ ). The addition of robust data from new methods for quantifying predation may help fill this crucial gap for future modeling efforts. Our results, that predation was greatest at maximum positive water velocities (outgoing tide) and lowest at more negative water velocities (incoming tide), are in contrast with those of Anderson et al. (2005), who found that

\footnotetext{
${ }^{4}$ Hendrix, N. 2008. A statistical model of Central Valley Chinook incorporating uncertainty: description of Oncorhynchus Bayesian analysis (OBAN) for winter run Chinook, 18 p. R2 Resource Consultants Inc., Redmond, WA. [Available at website, accessed November 2014.]
}

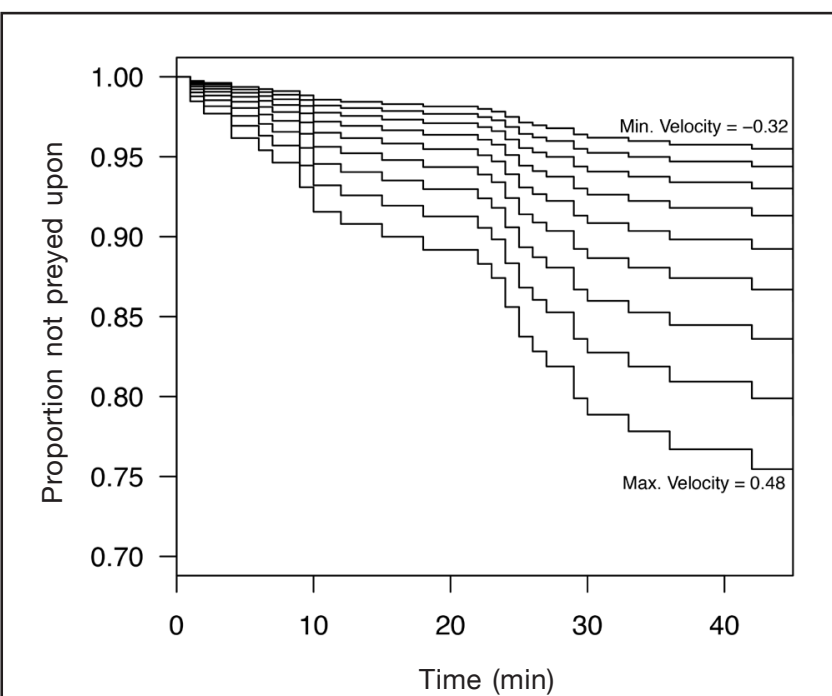

Figure 4

Estimated survival function for the Cox regression of time to predation over a series of water velocities from the minimum (negative) to the maximum (positive) water velocities by increments of $0.1 \mathrm{~m} / \mathrm{s}$.

survival of juvenile salmon was influenced more by travel distance than travel time or velocity. However, there are some important differences between studies. First, we conducted our study on a much smaller spatial and temporal scale that quantified individual predation events and therefore characterized more proximate, short-term processes. Secondly, our study system was strongly tidally influenced, to the extent that tidal water movements may have substantially affected predator behavior.

Acoustic tag technology for basin-scale studies has become the standard for assessing movement and survival of fish, particularly in salmonids (Perry et al., 2010; Michel et al., 2013). However, these studies are often expensive and do not reveal the mechanisms or locations of mortality. Although researchers are developing acoustic tags that report predation events through a change in tag ID code, it may be hours to days before the digestion-based processes trigger the predation event to be detected by a receiver (Afentoulis and Schultz, 2014). Furthermore, acoustic tags designed to report predation events do not identify predator species or distinguish the difference between predation events and the scavenging of tagged fish after some other cause of mortality. As such, alternative methods and instrumentation, such as PERs are needed to complement acoustic tagging studies to evaluate predation mortality.

Fishery and water managers often call for investigations of predator control along with predator habitat manipulation as a management tool, and some predator-reduction studies have been implemented (e.g., Porter, 2011). Evaluations of predator control and preda- 
tor habitat manipulation require estimates of pretreatment predation rates and of how predation rates fluctuate with changes in predator abundance and habitat condition. These predation rates may be estimated in various ways. One method involves conducting coordinated studies of predator and prey distribution and abundance, in combination with predator diet studies (Rieman et al., 1991). However, this approach is labor intensive and time consuming, making it difficult to replicate in several different areas at once. Considering that the Sacramento-San Joaquin Delta has a complex suite of hydrological processes and geography (the south delta is especially affected by municipal and freshwater export processes), there is potential for substantial spatial heterogeneity in fish predation rates, thus requiring replication of predation rate studies in many different areas and habitats.

Diet-based predation studies lack statistical power when prey species of concern are rare and make up only a small part of a predator's diet. Predation-event recorders (PER) provide an alternative that has the advantage of being relatively inexpensive and also capable of being implemented over a broad spatial and temporal scale. The intent of this method is not to quantify absolute predation rates, but rather to provide a relative comparison of predation rates among study areas to substantiate predator density and environmental covariate hypotheses. Additionally, the identification of predation "hotspots" gives us insight into the underlying physical and biological mechanisms that contribute to observed mortality. By simultaneously collecting environmental data, we were able to construct and select appropriate statistical models to describe the contributing factors that affect predation.

Fish ecologists have used stationary tethers to study predation on fishes (Linehan et al., 2001; Adams et al., 2004; Chittaro et al., 2005). However, our free drifting PERs have features that are more useful in free-flowing rivers. Drifting PERs may be the preferred design under conditions where movements through a habitat feature are favored, resulting in a more natural presentation and larger area sampled. This is especially important when assessing interactive effects of variables such as water exports, flow rate, total discharge and tidal mechanics on the movement and survival of young fish. Alternatively, anchored PERs enable targeted sampling around specific habitat features like the lower water column in deeper river sections, littoral habitats, or around fixed structures. The PER design has the advantage that it may be altered (size, shape etc.) for sampling in different conditions. Owing to the tidal nature and relatively low current velocities in our study site, we designed our PERs to maximize the effect of subsurface current forces in order to counteract the effect of wind. PERs may also be adapted to study predation on other fish species, such as delta smelt (Hypomesus transpacificus) or steelhead (Oncorhynchus mykiss) that also occur in the Sacramento-San Joaquin Delta, and it may be modified for use in rivers, lakes, estuaries and coastal ocean environments.

\section{Acknowledgments}

We would like to thank the many people who assisted with fieldwork, particularly M. Sabal, V. Lo, T. Brown, B. Lehman, and M. Miller. In addition, M. Henderson and F. Cordoleani provided insightful comments on early drafts and three anonymous reviewers provided helpful suggestions during the review process. The California Department of Water Resources funded this work under agreement no. 46-10100 with the National Marine Fisheries Service. Material and logistical support was also provided by The National Marine Fisheries Service Southwest Fisheries Science Center, Santa Cruz, CA.

\section{Literature cited}

Adams, A. J., J. V. Locascio, and B. D Robbins.

2004. Microhabitat use by a post-settlement stage estuarine fish: evidence from relative abundance and predation among habitats. J. Exp. Mar. Biol. Ecol. 299:17-33. Article

Afentoulis, V., and A. Schultz.

2014. Efficacy test of a tag designed to signal when a fish has been consumed. In Challenges, collaboration, solutions. California-Nevada Chapter of the American Fisheries Society $48^{\text {th }}$ Annual Conference; Sacramento, CA, 27-29 March, p. 29. Calif.-Nev. Chapter Am. Fish. Soc., Davis, CA. [Available at website.]

Anderson, J. J., E. Gurarie, and R. W. Zabel.

2005. Mean free-path length theory of predator-prey interactions: application to juvenile salmon migration. Ecol. Model. 186:196-211. Article

Bennett, W. A., and P. B. Moyle.

1996. Where have all the fishes gone: interactive factors producing fish declines in the Sacramento-San Joaquin estuary. In San Francisco Bay: the ecosystem, vol. 1 (J. T. Hollingbaugh, ed.), p. 519-542. Pacific Division, American Association for the Advancement of Science, San Francisco, CA

Buchanan, R. A., J. R. Skalski, P. L. Brandes, and A. Fuller. 2013. Route use and survival of juvenile Chinook salmon through the San Joaquin River Delta. North Am. J. Fish. Manage. 33:216-229. Article

Burnham, K. P., and D. R. Anderson.

2002. Model selection and multimodel inference: a practical information-theoretic approach, $2^{\text {nd }}$ ed., 488 p. Springer, New York.

Brandes, P. L., and J. S. McLain.

2001. Juvenile Chinook salmon abundance, distribution and survival in the Sacramento-San Joaquin estuary. In Contributions to the biology of Central Valley salmonids, vol 2. Calif. Dep. Fish Game, Fish. Bull. 179 (R. L. Brown, ed.), p. 39-136. Calif. Dep. Fish Game, Sacramento, CA.

Chittaro, P. M., P. Usseglio, and P. F. Sale.

2005. Variation in fish density, assemblage composition and relative rates of predation among mangrove, seagrass and coral reef habitats. Environ. Biol. Fish. 72:175-187. Article

Cox, D. R.

1972. Regression models and life-tables. J. R. Stat. Soc., Ser. B 34:187-220. 
Dormann, C. F., J. Elith, S. Bacher, S. Bachmann, G. Carl, G. Carré, J. R. García Marquéz, B. Gruber, B. Lafourcade, P. J. Leitão, T. Münkemüller, C. McClean, P. E. Osborne, B. Reineking, A. K. Skidmore, D. Zurell, and S. Lautenbach.

2013. Collinearity: a review of methods to deal with it and a simulation study evaluating their performance. Ecography 36(1):27-46. Article

Diez, D. M.

2013. OIsurv: survival analysis supplement to OpenIntro guide. [Available at website, accessed June 2015.]

Lindley, S. T., and M. S. Mohr.

2003. Modeling the effect of striped bass (Morone saxatalis) on the population viability of Sacramento River winter-run Chinook salmon (Oncorhynchus tshawytscha). Fish. Bull. 101:321-331.

Linehan, J. E., R. S. Gregory, and D. C. Schneider. 2001. Predation risk of age-0 cod (Gadus) relative to depth and substrate in coastal waters. J. Exp. Mar. Biol. Ecol. 263:25-44. Article

Michel, C. J., A. J. Ammann, E. D. Chapman, P. T. Sandstrom, H. E. Fish, M. J. Thomas, G. P. Singer, S. T. Lindley, A. P. Klimeley, and R. B. MacFarlane.

2013. The effects of environmental factors on the migratory movement patterns of Sacramento River yearling late-fall run Chinook salmon (Onchorhynchus tshawytscha). Environ. Biol. Fish. 96:257-2571. Article

Mueller, J. E.

1968. An introduction to the hydraulic and topographic sinuosity indexes. Ann. Assoc. Am. Geogr. 58:371-385.

Mount, J., W. Bennett, J. Durand, W. Fleenor, E. Hanak,. J. Lund, and P. Moyle.

2012. Aquatic ecosystem stressors in the Sacramento-San Joaquin Delta, 22 p. Public Policy Inst. California, San Francisco. [Available from website, accessed October 2014.]

Newman, K. B.

2003. Modelling paired release-recovery data in the pres- ence of survival and capture heterogeneity with application to marked juvenile salmon. Stat. Model. 3:157-177. Article

Newman, K. B., and J. Rice.

2002. Modeling the survival of Chinook salmon smolts outmigrating through the lower Sacramento River system. J. Am. Stat. Assoc. 97:983-993. Article

Perry, R. W., J. R. Skalski, P. L. Brandes, P. L. Sandstrom, A. P. Klimley, A. Ammann, and B. MacFarlane.

2010. Estimating survival and migration route probabilities of juvenile Chinook salmon in the SacramentoSan Joaquin River Delta. North Am. J. Fish. Manage. 30:142-156. Article

Porter, R.

2011. Report on the predation index, predator control fisheries, and program evaluation for the Columbia River Basin Experimental Northern Pikeminnow Management Program, 124 p. U.S. Dep. Energy, Bonneville Power Administration, Portland, OR. [Available at website, accessed October 2014.]

Pyper, B. T., Garrison, and S. Cramer.

2013. Analysis of trawl efficiency at Chipps Island using coded-wire-tagged releases of juvenile Chinook salmon, 97 p.. Cramer Fish Sciences, Gresham, OR. [Available at website, accessed October 2014.]

$\mathrm{R}$ Core Team.

2015. R: a language and environment for statistical computing. R Foundation for Statistical Computing, Vienna, Austria. [Available at website, accessed March 2015.]

Rieman, B. E., R. C. Beamesderfer, S Vigg, and T. P. Poe.

1991. Estimated loss of juvenile salmonids to predation by northern squawfish, walleyes, and smallmouth bass in the John Day Reservoir, Columbia River. Trans. Am Fish. Soc. 120:448-458. website

Somerton, D. A., B. S. Kikkawa, and C. D. Wilson.

1988. Hook timers to measure the capture time of individual fish. Mar. Fish. Rev. 50(2):1-5. 